\title{
Frequency of Prescriptions that could Cause Harmful Drug Interactions and Usefulness of Providing such Information
}

\author{
Kazuhiro HARADA*1,2 Kumio IKEBA*3 Masafumi OKADA*4 \\ Shinichiro KOMIYAMA*5 Fujio SENBA*6 Michikazu OHBAYASHI*7 \\ Keiko NAKANO*8 Yasuko TOMOKIYO*9 Shoji YAMAZAKI*10 \\ and Akio Fujimura*1
}

(Received on January 10, 2002)

*1 Department of Clinical Pharmacology, Jichi Medical School 3311-1 Yakushiji, Minamikawachi-machi, Kawachi-gun, Tochigi 329-0498, Japan

*2 Department of Internal Medicine, Kasaoka Daiichi Hospital

*3 Department of Pharmacy, Wara-mura Hospital

*4 Department of Pharmacy, Kumihama Hospital

*5 Department of Pharmacy, Yoka Hospital

*6 Department of Pharmacy, Kensei General Hospital

*7 Apple Pharmacy *8 Pinokio Pharmacy ${ }^{* 9}$ Gion Pharmacy

*10 Department of Pharmacy, Jichi Medical School Hospital

\begin{abstract}
We prospectively surveyed how frequently drugs were prescribed that could cause harmful drug interactions, and evaluated the effect of providing the physicians with information concerning drug interactions on the frequency of such prescriptions.

At seven pharmacies, the pharmacists checked how many pre-selected concurrent uses of the drugs were prescribed for 3 months. At one hospital, the physicians were provided with the information concerning drug interactions, and the change in the frequency of these prescriptions was surveyed.

Contraindicated drug combinations were scarcely prescribed; cisapride and erythromycin (or clarithromycin) was prescribed at 0.5 per 10,000. Other combinations of drugs that could be potentially harmful were not rarely prescribed. After providing the information, such concurrent medications were less often prescribed.

Effective means of communicating information about drug interactions are needed. Providing clinicians with the information given by pharmacists in daily practice was thought to be one such means.
\end{abstract}

Key words : drug interaction, information, prescription, pharmacist

\section{Introduction}

When prescribing drugs, clinicians must be alert to drug interactions, in order to avoid serious adverse drug reactions and to achieve efficacious drug treatment. Within the last decade, the understanding of drug interactions has been dramatically advanced. However, our previous studies have shown that, generally, clinicians do not have sufficient knowledge about drug interac-

*1 自治医科大学臨床薬理学

干 329-0498 栃木県河内郡南河内町薬師寺 3311-1

$* 2$ 笠岡第一病院内科 $* 3$ 和良村国保病院薬局 $* 4$ 久

美浜病院薬局 $* 5$ 八鹿病院薬局 $* 6$ 県西総合病院薬局

*7 アップル薬局 *8 ピノキオ薬局 *9 祇園薬局

$* 10$ 自治医科大学附属病院薬剂部 tions and in daily practice, pharmacists often encounter prescriptions that could cause harmful drug interactions $^{1,2)}$.

Although clinicians have been provided with more information concerning drug interactions than before ${ }^{2)}$, we suppose that a considerable number of prescriptions including drugs that can cause harmful drug interactions are still prescribed. We think that it is important to clarify how often such a combination is prescribed and to take appropriate measures to cope with the situation. To our knowledge, however, such a study has not been performed to date.

We prospectively surveyed, therefore, how frequently the concurrent use of drugs that can cause harmful drug 
interactions are prescribed. In addition, we evaluated the effect of providing physicians with the information concerning the drug interactions in daily practice on the frequency of such prescriptions.

\section{Methods}

\section{Study 1}

Seven pharmacies took part in this study. Four pharmacies were affiliated with a general hospital practicing primary care medicine and the other three were located near Jichi Medical School Hospital. We chose 18 drug combinations (Table 1) that can cause a harmful interaction. Six of them were contraindicated combinations in Japan. At each pharmacy, the pharmacists checked how many of these concurrently used drugs were prescribed for 3 months (from May 1 to July 31, 1999).

We showed the data with $95 \%$ confidence intervals $(95 \% \mathrm{CI})$ and analyzed using $\chi$-test, whether the difference in the frequency of the prescription exists or not between the four general hospital pharmacies and the three pharmacies near Jichi Medical School.

\section{Study 2}

At one hospital in which concurrent use of these drugs was rather frequent, the physicians were provided with pertinent information concerning the drug for three months, and the frequency of the prescriptions was surveyed in the same manner during the following three months.

We prepared, for each drug combination, a leaflet on which the information about the interaction was summarized. On the leaflets, the following information was briefly mentioned : the general concept, the mechanism, the pharmacokinetic data, and the way to avoid the harmful effect of the interaction. The drug combinations for which we prepared the leaflets were those shown in Table 2. To provide the physicians with the information, the pharmacists gave them the leaflet concerning the interaction they prescribed, when the physicians prescribed the concurrent use of drugs.

The data was analyzed, using $x$-test, whether the frequency of the prescription was decreased by the information.

\section{Results}

\section{Study 1}

The total number of the prescriptions the pharmacies received during the period was about $178,000: 151,000$ at the four general hospital pharmacies and 27,000 at the three pharmacies located near Jichi Medical School Hospital.

Table 1 shows the number and frequency (represented as per 10,000) of the concurrent use of the drugs. Contraindicated drug combinations were scarcely prescribed; cisapride and erythromycin (or clarithromycin) was prescribed at 0.5 per 10,000 , but others were not prescribed. The other combinations of drugs that need careful attention to interaction were sometimes prescribed.

The frequency of the prescriptions varied considerably among the pharmacies. As shown in Table 1 , in some (6 out of 18) combinations of the drugs, statistically more prescriptions were received in the general hospital pharmacies than in the pharmacies located near Jichi Medical School Hospital.

\section{Study 2}

Table 2 shows the change in the frequency of the prescription before and after the three-month information period. The frequency was decreased for each prescription, and the following combinations were statistically significant $(\mathrm{p}<0.05)$; triazolam plus cimetidine and pravastatin (or simvastatin) plus bezafibrate.

\section{Discussion}

Among the six pre-selected contraindicated drug combinations, cisapride and erythromycin (or clarithromycin) was actually prescribed, although the frequency of these prescriptions was small. This might be because these drugs were widely prescribed and the information concerning the drug interaction was still insufficient. The manufacturors of cisapride have stated that rare cases of serious cardiac arrhythmias, including ventricular arrhythmia and Torsade de Pointes associated with QT prolongation have been reported in patients taking cisapride in combination with erythromycin or clarithromycin. Because of its seriousness, the concurrent use of these drugs is contraindicated ${ }^{3)}$. However, their warnings seemed to be ineffective. Smalley et $\mathrm{al}^{4)}$ showed that the FDA's 1998 regulatory action regarding cisapride use had no preventive effect on contraindicated cisapride use, suggesting that more effective ways to communicate information about drug safety are needed. 
Table 1 The Combinations of the Drugs We Surveyed and the Number and Frequency (per 10,000) of the Prescriptions

\begin{tabular}{|c|c|c|c|}
\hline & $\begin{array}{c}\mathrm{G}-\mathrm{H} \\
\mathrm{n}(/ 10,000)\end{array}$ & $\begin{array}{c}\mathrm{M}-\mathrm{S} \\
\mathrm{n}(/ 10,000)\end{array}$ & $\begin{array}{c}\text { Total } \\
\mathrm{n}(/ 10,000: 95 \% \mathrm{CI})\end{array}$ \\
\hline \multicolumn{4}{|l|}{ Triazolam } \\
\hline+ Itraconazole or Fluconazole ${ }^{\#}$ & 0 & 0 & 0 \\
\hline +Erythromycin or Clarithromycin & $8(0.5)$ & $1(0.4)$ & $9(0.5: 0.23-0.96)$ \\
\hline+ Cimetidine & $51(3.4)$ & $3(1.1)^{*}$ & $54(3.0: 2.3-4.0)$ \\
\hline +Diltiazem & $30(2.0)$ & $4(1.5)$ & $34(1.9: 1.3-2.7)$ \\
\hline \multicolumn{4}{|l|}{ Terfenadine or Astemizole } \\
\hline +Itraconazole or Fluconazole $e^{\#}$ & 0 & 0 & 0 \\
\hline +Erythromycin or Clarithromycin ${ }^{\#}$ & 0 & 0 & 0 \\
\hline \multicolumn{4}{|l|}{ Cisapride } \\
\hline +Itraconazole or Fluconazole $\mathrm{e}^{\#}$ & 0 & 0 & 0 \\
\hline +Erythromycin or Clarithromycin $\#$ & $9(0.6)$ & $0^{*}$ & $9(0.5: 0.23-0.96)$ \\
\hline \multicolumn{4}{|l|}{ Enoxacin, Norfloxacin, or Ciprofloxacin } \\
\hline+ Fenbufen or Ketoprofen ${ }^{\#}$ & 0 & 0 & 0 \\
\hline +other Non-steroidal Anti-inflammatory Drugs & $180(11.9)$ & $19(7.0)^{*}$ & $199(11.2: 9.7-12.9)$ \\
\hline \multicolumn{4}{|l|}{ Rifampicin } \\
\hline+ Calcium channel blockers & $7(0.5)$ & $0^{*}$ & $7(0.4: 0.16-0.81)$ \\
\hline+ Warfarin & 0 & 0 & 0 \\
\hline \multicolumn{4}{|l|}{ Theophylline } \\
\hline + Ticlopidine & $56(3.7)$ & $7(2.6)$ & $63(3.5: 2.7-4.5)$ \\
\hline+ Enoxacin or Ciprofloxacin & $6(0.4)$ & $2(0.7)$ & $8(0.5: 0.19-0.89)$ \\
\hline \multicolumn{4}{|l|}{ Magnesium or Aluminium-containing Antacids } \\
\hline +Enoxacin, Norfloxacin, or Ciprofloxacin & $36(2.4)$ & $2(0.7)^{*}$ & $38(2.1: 1.5-2.9)$ \\
\hline \multicolumn{4}{|l|}{ Metoclopramide } \\
\hline +Sulpiride, Tiapride or Haloperidol & $6(0.4)$ & $0^{*}$ & $6(0.3: 0-0.40)$ \\
\hline \multicolumn{4}{|l|}{ Digoxin } \\
\hline +Verapamil & $31(2.1)$ & $4(1.5)$ & $35(2.0: 1.4-2.7)$ \\
\hline \multicolumn{4}{|l|}{ Pravastatin or Simvastatin } \\
\hline+ Bezafibrate & $57(3.8)$ & $25(9.3)$ & $82(4.6: 3.7-5.7)$ \\
\hline
\end{tabular}

G-H, the four general hospital pharmacies (total number of prescriptions : 151,000)

M-S, the three pharmacies near Jichi Medical School Hospital (total number of prescriptions : 27,000)

\# contraindicated combination $* \mathrm{p}<0.05$ vs G-H

Table 2 The Number and Frequency (per 10,000) of the Prescriptions before and after Providing Information about the Drug Interaction in the Pharmacy of a General Hospital

\begin{tabular}{|c|c|c|c|}
\hline & $\begin{array}{c}\text { Before } \\
\mathrm{n}(/ 10,000)\end{array}$ & $\begin{array}{c}\text { After } \\
\mathrm{n}(/ 10,000)\end{array}$ & $\begin{array}{c}\text { Reduction Ratio } \\
\%\end{array}$ \\
\hline \multicolumn{4}{|l|}{ Cisapride } \\
\hline+ Erythromycin or Clarithromycin ${ }^{\#}$ & $2(3.1)$ & $1(1.7)$ & 45 \\
\hline \multicolumn{4}{|l|}{ Triazolam } \\
\hline +Erythromycin or Clarithromycin & $2(3.1)$ & 0 & 100 \\
\hline + Cimetidine & $24(37.7)$ & $2(3.5)^{*}$ & 91 \\
\hline +Diltiazem & $7(10.9)$ & $4(7.0)$ & 36 \\
\hline \multicolumn{4}{|l|}{ Enoxacin, Norfloxacin, or Ciprofloxacin } \\
\hline+ Non-steroidal Anti-inflammatory Drugs & $4(6.3)$ & $2(3.5)$ & 44 \\
\hline \multicolumn{4}{|l|}{ Theophylline } \\
\hline+ Ticlopidine & $8(12.6)$ & $6(10.5)$ & 17 \\
\hline \multicolumn{4}{|l|}{ Pravastatin or Simvastatin } \\
\hline+ Bezafibrate & $4(6.3)$ & $0^{*}$ & 100 \\
\hline
\end{tabular}

\# contraindicated combination ${ }^{*} \mathrm{p}<0.05$ vs Before.

Total number of prescriptions before and after the information was 6,400 and 5,700 , respectively. 
There are many more drug combinations that are not contraindicated but need special attention to the drug interaction. This survey showed that such a concurrent use of the drugs was not rarely prescribed. The chance will be increased when a patient visits more than one clinic. In this survey such a case could not be checked. So the actual frequency of the concurrent use of the drugs is thought to be higher.

It is unknown whether the clinicians actually considered the possibility of the drug interaction when they prescribed the drugs. However, as shown by our previous studies ${ }^{1,2)}$, clinicians, generally, do not have enough knowledge about drug interactions and pay little attention to them in daily practice, and most of the pharmacists do not take any special measures for such situations. There are many chances therefore, that patients are given drugs that might cause a harmful drug interaction without any particular caution made.

In 1993, 15 people died as a result of the interaction between sorivudine and fluorouracil analogues in Japan. This tragedy led us to realize the importance of drug interactions ${ }^{5}$. But it is still necessary to improve the system of transmitting information and to take concrete measures to cope with prescriptions that can cause harmful drug interactions. This study showed that the information given by pharmacists in clinical practice might be very efficacious.

Our previous study showed, however, that few pharmacists give advice about the drug interactions to the clinicians ${ }^{2}$. In order to provide the information easily and effectively for clinicians in clinical practice, we made leaflets summarizing the drug interaction.

We evaluated whether this method would be effective for reducing the concurrent use of drugs which might cause a harmful drug interaction. In the hospital, the pharmacists provided the physicians with the information by using leaflets when the concurrent medications were prescribed. After providing the information, the concurrent medications were less prescribed. This study showed that the reduction in the prescription of cisapride and erythromycin or clarithromycin was $45 \%$. The frequency of concurrent use of other drugs was also reduced to about half.

The following considerations should be taken into account to avoid harmful drug interactions: (1) physicians should recognize and be alerted to drug interactions, (2) proper information concerning drug interac- tions should be given to physicians as well as pharmacists, and (3) pharmacists should properly check prescriptions and provide physicians with necessary information.

Our previous study ${ }^{1}$ showed that the largest source of the information concerning drug interactions was pharmaceutical companies. Pharmaceutical companies need to give information more effectively to physicians and pharmacists. In addition, more education concerning clinical pharmacology for students in medical and pharmaceutical schools should be conducted.

Using computers is one of the most efficient methods of detecting contraindicated drug combinations ${ }^{6}$. But pharmacists have to have much knowledge also about drug interactions, and should not only check the prescriptions but also communicate well with and advise physicians.

Our present prospective study showed that concurrent use of the drugs that can cause harmful drug interactions were not rarely prescribed, although contraindicated combinations were rarely prescribed. To achieve safe and proper drug treatment, effective ways to communicate the information about drug interactions are needed. We think that providing physicians with the information by pharmacists in daily practice is one of the most effective ways.

\section{Acknowledgement}

We thank Mr. Kawaguchi (Clinical Pharmacology, Jichi Medical School) for his suggestions in statistical analysis.

\section{References}

1) Harada, K., Arakawa, M., Yamazaki, S., et al. : Survey on transmission of information to clinicians regarding drug interactions. Jpn. J. Clin. Pharmacol. Ther., 29 : 715-720 (1998). (in Japanese)

2) Harada, K., Yamazaki, S., Arakawa, M., et al. : Survey of the attitudes of pharmacists and medical representatives toward drug interactions in daily practice. Jpn. J. Clin. Pharmacol. Ther., 30:783-791 (1999). (in Japanese)

3) Janssen-Cilag UK, Dear Doctor letter (November 1995).

4) Smalley, W., Shatin, D., Wysowski, D. K., et al. : Contraindicated use of cisapride : impact of food and drug administration regulatory action. JAMA, $284: 3036-3039$ (2000).

5) Hamada, C., Koide, D., Kusunoki, T., et al. : Questionnaires relating to the transmission of drug information relating the interaction of sorivudine. Jpn. J. Clin. Pharmacol. Ther., 25 : 583-596 (1994). (in Japanese)

6) McMullin, S. T., Reichley, R. M., Watson, L. A., et al. : Impact of a web-based clinical information system on cisapride drug interactions and patient safety. Arch. Intern. Med., 159 : 2077-2082 (1999). 